\title{
Identification of Tick Species Collected from Wild Boars and Habitats of Wild Boars and Domestic Pigs in the Republic of Korea
}

\author{
Jeong-Byoung Chae ${ }^{1}$, Jun-Gu Kang ${ }^{1}$, Heung-Chul Kim², Sung-Tae Chong ${ }^{2}$, In-Yong Lee ${ }^{3}$, Nam-Shik Shin', \\ Joon-Seok Chae ${ }^{1, *}$ \\ ${ }^{1}$ Laboratory of Veterinary Internal Medicine, BK21 Plus Program for Creative Veterinary Science Research, Research Institute for Veterinary Science \\ and College of Veterinary Medicine, Seoul National University, Seoul 08826, Korea; ${ }^{25}$ th Medical Detachment, 168th Multifunctional Medical Battalion, \\ 65th Medical Brigade, Unit 15247, APO AP 96205-5247, USA; ${ }^{3}$ Department of Environmental Medical Biology, Yonsei University College of Medicine, \\ Seoul 03722, Korea; ${ }^{4}$ Laboratory of Zoo and Wildlife Medicine, College of Veterinary Medicine, Seoul National University, Seoul 08826, Korea
}

\begin{abstract}
Tick is one of the most important arthropods in the transmission of vector-borne diseases. In this study, we investigated the abundance and species of ticks associated with swine and their habitats to assess the risk of spread of tick-borne diseases in host species, such as wild boars. Ticks were collected from 24 grazing or traditionally reared domestic pig farms and 8 habitats of wild boars in 8 provinces and 1 city in the Republic of Korea, by using the dragging and flagging methods. Ticks were also collected directly from 49 wild boars by using fine forceps. A total of 9,846 hard ticks were collected, including 4,977 Haemaphysalis longicornis, 4,313 Haemaphysalis flava, 508 Ixodes nipponensis, 1 Ixodes turdus, and 47 Amblyomma testudinarium. A total of 240 hard ticks were collected from 49 wild boars, including $109 \mathrm{H}$. flava, $84 \mathrm{H}$. longicornis, and $47 \mathrm{~A}$. testudinarium. A total of 578 hard ticks were collected from areas around domestic pig farms. Only 2 hard tick species, $546 \mathrm{H}$. longicornis and $32 \mathrm{H}$. flava, were collected from these areas. A total of 9,028 hard ticks were collected from wild boars of 8 habitats, including 4,347 H. longicornis, 4,172 H. flava, 508 I. nipponensis, and $1 \mathrm{I}$. turdus. A. testudinarium was collected only from wild boars, and I. nipponensis and $\mathrm{l}$. turdus were collected only from the habitats of wild boars.
\end{abstract}

Key words: Haemaphysalis Iongicornis, Haemaphysalis flava, Ixodes nipponensis, Ixodes turdus, Amblyomma testudinarium, tick, wild boar, pig

\section{INTRODUCTION}

Ticks are small, hematophagous arthropods that are obligate parasites of vertebrates. Tick consists of Merastigmata, Mesostigmata, Prostigmata, and Astigmata, among which Merastigmata belongs to Ixodidae, Argasidae, and Nuttalliellidae [1]. The habitats of all ticks are associated with their hosts and local environment; however, Argasidae have a more limited range of off-host habitats [2]. Tick habitats are affected by many factors, including climate change, and more specifically direct changes in temperature, rainfall, and humidity, as well as via indirect influences on vegetation and hosts [3].

The Eurasian wild boar (Sus scrofa) has the widest distribu-

\footnotetext{
- Received 5 November 2016, revised 15 February 2017, accepted 19 March 2017.

*Corresponding author (jschae@snu.ac.kr)

(c) 2017, Korean Society for Parasitology and Tropical Medicine

This is an Open Access article distributed under the terms of the Creative Commons

Attribution Non-Commercial License (http://creativecommons.org/licenses/by-nc/4.0)

which permits unrestricted non-commercial use, distribution, and reproduction in any

medium, provided the original work is properly cited.
}

tion of all members of the pig family and is a reservoir of many viruses, bacteria, and parasites, including ticks that can infect domestic animals and humans [4]. The distribution and population of wild boars is increasing because of many factors, such as global climatic change and food resources, and the distribution of wild boars has now extended to the Republic of Korea (ROK) [5-7].

African swine fever (ASF) caused by a contagious DNA virus of the Asfarviridae family is one of the major viral diseases in swine species, and causes high mortality in domestic pigs [8]. African swine fever virus (ASFV) is transmitted to swine species during blood-feeding by soft ticks, Ornithodoros spp., which results in a high-titer, persistent infection of ASFV [9]. Although there are no reports of ASF, the transmission of this infection should be investigated as the range of wild boar habitats has increased in the ROK, and ASF is an important aspect of ASFV transmission. Soft tick detection, therefore, is imperative in investigating the spread of ASF in swine species.

The risk is higher because of unreported transport of ticks 
into the ROK. As ticks may be imported carrying many pathogens that can transmit vector-borne diseases, thereby increasing the spread of vector-borne diseases, it is essential to understand the current distribution of ticks in the ROK.

\section{MATERIALS AND METHODS}

\section{Study sites}

Ticks were collected from 32 different sampling sites in 8 provinces in the ROK in 2013. Total 24 grazing or traditional domestic pig farms and 8 habitats of wild boars (S. scrofa) were selected in 8 provinces and 1 city (Gangwon-do, Gyeonggi-do, Chungcheongbuk-do, Chungcheongnam-do, Jeollabukdo, Jeollanam-do, Gyeongsangbuk-do, Jeju-do, and Incheon Metropolitan City, Fig. 1). Habitats of wild boars were determined from the number of wild boar occurrences in 2012 and 2013 recorded by the Korean Wildlife Management Association.

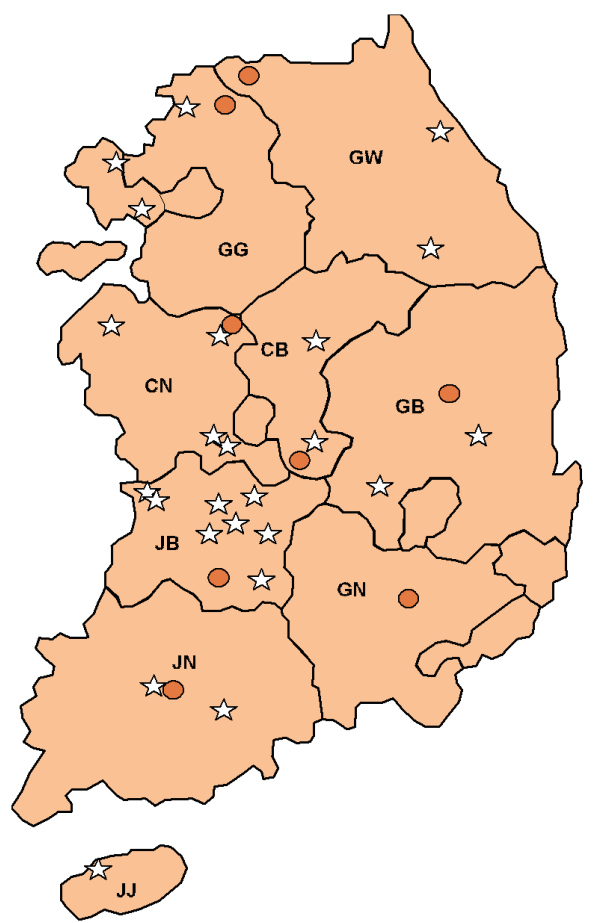

Fig. 1. Sampling sites of collected ticks from near pig farms and the habitats of wild boars (Sus scrofa). Star shapes were the sites of collected ticks from grazing or traditionally reared domestic pig farms. Round shapes were the sites of collected ticks from 8 habitats of wild boars. GG; Gyeonggi-do, GW; Gangwon-do, CB; Chungcheongbuk-do, CN; Chungcheongnam-do, JB; Jeollabukdo, JN; Jeollanam-do, GB; Gyeongsangbuk-do, GN; Gyeongsangnam-do, JJ; Jeju-do.

\section{Tick collection from swine habitats}

The dragging and flagging methods were used to collect IXodidae ticks on the ground. For the dragging, a flannel cloth (1.5 m long $\times 1.0 \mathrm{~m}$ wide), a wooden dowel (1.2 m long, 4.0 $\mathrm{cm}$ diameter), and a 4.0-m-long nylon rope was used. The cloth was attached to a wooden dowel and each end of the nylon rope was tied to each end of the wooden dowel. This tick dragging method was modified as described in a previous study [10]. The tick flag was similar to the tick drag, except that an aluminum pole $(1.0 \mathrm{~m}$ long $\times 2.0 \mathrm{~cm}$ diameter) was used instead of a wooden dowel and nylon rope.

After laying the flannel cloth on the ground or vegetation, dragging was conducted by slow-walking, stopping at $10 \mathrm{~m}$ intervals, and removing ticks attached to both sides of the cloth using fine forceps. Removed ticks were placed in $15 \mathrm{ml}$ tubes, with 1 picked grass blade to maintain humidity, and transported to the laboratory. Collected ticks were identified to species level and developmental stage, using a microscope (SZH10, Olympus, Tokyo, Japan) and taxonomic identification keys [11]. Collected ticks were then stored in $2 \mathrm{ml}$ microcentrifuge tubes at $-20^{\circ} \mathrm{C}$.

\section{Tick collection from wild boars}

Wild boars were captured by the Korean Wildlife Management Association following the guidelines for the capturing works of wild animals. Ticks were collected directly from wild boars using fine forceps. They were stored in $15 \mathrm{ml}$ tubes, with 1 picked grass blade, transported to the laboratory and identified to developmental stages and species level, using a microscope and taxonomic identification keys [11].

\section{Soft tick collection}

A portable vacuum (GE-HY9996, Plusmate, China) was used to collect soft ticks. In pig farms, we vacuumed the borders of pig farms, and materials gathered were stored in ice containers and transported to the laboratory. Gathered material was put onto a flannel cloth, and only soft ticks were separated from the material to identify.

\section{RESULTS}

A total of 9,846 ticks (larvae, nymphs, and adults) belonging to 3 genera and 5 species were collected in 2013, including 4,977 Haemaphysalis longicornis; 4,313 Haemaphysalis flava; 508 Ixodes nipponensis; 1 Ixodes turdus, and 47 Amblyomma testudina- 
rium (Table 1). The samples collected were sorted based on the developmental stages as follows: 310 adults, 609 nymphs, and 4,058 larvae of H. longicornis (50.5\%); 243 adults, 825 nymphs, and 3,245 larvae of $H$. flava (43.8\%); 16 adults, 20 nymphs, and 472 larvae of I. nipponensis (5.2\%); 47 adults of A. testudinarium (0.48\%); and 1 nymph of I. turdus (0.01\%).

Total 49 wild boars were captured from 36 sites in 7 provinces (Gangwon-do, Gyeonggi-do, Chungcheongbuk-do, Chungcheongnam-do, Jeollanam-do, Gyeongsangbuk-do, and Gyeongsangnam-do), and 240 hard ticks (Ixodidae) were col-

Table 1. Collection of larvae, nymphs, and adults of ixodid ticks from wild boars, grazing or traditionally reared domestic pig farms and near the areas, and the habitats of wild boars, 2013

\begin{tabular}{|c|c|c|c|c|c|}
\hline \multirow{2}{*}{ Tick species } & \multirow{2}{*}{ No. of larvae } & \multirow{2}{*}{ No. of nymphs } & \multicolumn{2}{|c|}{ No. of adults } & \multirow{2}{*}{$\begin{array}{l}\text { Total no. of ticks } \\
\text { collected }\end{array}$} \\
\hline & & & Male & Female & \\
\hline Haemaphysalis longicornis & 4,058 & 609 & 44 & 266 & 4,977 \\
\hline Haemaphysalis flava & 3,245 & 825 & 147 & 96 & 4,313 \\
\hline Ixodes nipponensis & 472 & 20 & 12 & 4 & 508 \\
\hline Ixodes turdus & 0 & 1 & 0 & 0 & 1 \\
\hline Amblyomma testudinarium & 0 & 0 & 26 & 21 & 47 \\
\hline Total & 7,775 & 1,455 & 229 & 387 & 9,846 \\
\hline
\end{tabular}

Table 2. Ticks collected from wild boars, 2013

\begin{tabular}{|c|c|c|c|c|c|c|c|}
\hline \multirow{2}{*}{ Province } & \multirow{2}{*}{$\begin{array}{c}\text { No. of } \\
\text { captured sites }\end{array}$} & \multirow{2}{*}{$\begin{array}{c}\text { No. of } \\
\text { wild boars }\end{array}$} & \multirow{2}{*}{ Tick species } & \multirow{2}{*}{ No. of nymphs } & \multicolumn{2}{|c|}{ No. adults } & \multirow{2}{*}{$\begin{array}{l}\text { Total no. of ticks } \\
\text { collected }\end{array}$} \\
\hline & & & & & Male & Female & \\
\hline \multirow[t]{4}{*}{ Gangwon-do } & 5 & 6 & A. testudinarium & 0 & 1 & 2 & 3 \\
\hline & & & H. flava & 0 & 0 & 1 & 1 \\
\hline & & & H. longicornis & 0 & 0 & 5 & 5 \\
\hline & & & Subtotal & 0 & 1 & 8 & 9 \\
\hline \multirow[t]{4}{*}{ Gyeonggi-do } & 3 & 3 & A. testudinarium & 0 & 0 & 0 & 0 \\
\hline & & & H. flava & 0 & 0 & 4 & 4 \\
\hline & & & H. longicornis & 0 & 0 & 6 & 6 \\
\hline & & & Subtotal & 0 & 0 & 10 & 10 \\
\hline \multirow[t]{4}{*}{ Chungcheongbuk-do } & 3 & 6 & A. testudinarium & 0 & 0 & 0 & 0 \\
\hline & & & H. flava & 0 & 1 & 3 & 4 \\
\hline & & & H. longicornis & 1 & 2 & 11 & 14 \\
\hline & & & Subtotal & 1 & 3 & 14 & 18 \\
\hline \multirow[t]{4}{*}{ Chungcheongnam-do } & 5 & 6 & A. testudinarium & 0 & 0 & 0 & 0 \\
\hline & & & H. flava & 0 & 50 & 13 & 63 \\
\hline & & & H. longicornis & 0 & 0 & 4 & 4 \\
\hline & & & Subtotal & 0 & 50 & 17 & 67 \\
\hline \multirow[t]{4}{*}{ Jeollanam-do } & 6 & 8 & A. testudinarium & 0 & 13 & 4 & 17 \\
\hline & & & H. flava & 0 & 0 & 0 & 0 \\
\hline & & & H. longicornis & 0 & 1 & 4 & 5 \\
\hline & & & Subtotal & 0 & 14 & 8 & 22 \\
\hline \multirow[t]{4}{*}{ Gyeongsangbuk-do } & 6 & 10 & A. testudinarium & 0 & 2 & 0 & 2 \\
\hline & & & H. flava & 0 & 1 & 6 & 7 \\
\hline & & & H. longicornis & 9 & 3 & 23 & 35 \\
\hline & & & Subtotal & 9 & 6 & 29 & 44 \\
\hline \multirow[t]{4}{*}{ Gyeongsangnam-do } & 8 & 10 & A. testudinarium & 0 & 10 & 15 & 25 \\
\hline & & & H. flava & 0 & 13 & 17 & 30 \\
\hline & & & H. longicornis & 0 & 0 & 15 & 15 \\
\hline & & & Subtotal & 0 & 23 & 47 & 70 \\
\hline \multirow[t]{4}{*}{ Total } & 36 & 49 & A. testudinarium & 0 & 26 & 21 & 47 \\
\hline & & & H. flava & 0 & 65 & 44 & 109 \\
\hline & & & H. longicornis & 10 & 6 & 68 & 84 \\
\hline & & & Total & 10 & 97 & 133 & 240 \\
\hline
\end{tabular}


lected from these wild boars (Table 2). H. flava (109 adults), $H$. longicornis (74 adults, 10 nymphs), and A. testudinarium (47 adults) were collected. A. testudinarium was collected only from wild boars. Forty-seven A. testudinarium in total were collected across 4 provinces, including 3 adults in Gangwon-do, 17 adults in Jeollanam-do, 2 adults in Gyeongsangbuk-do, and 25 adults in Gyeongsangnam-do. From the wild boars, we collected 109 H. flava (45.4\%), 84 H. longicornis (35.0\%), and $47 \mathrm{~A}$. testudinarium (19.6\%).

In total, 578 hard ticks were collected from 24 pig farms, or the areas around pig farms, in 8 provinces and 1 city (Gangwon-do, Gyeonggi-do, Chungcheongbuk-do, Chungcheongnam-do, Jeollabuk-do, Jeollanam-do, Gyeongsangbuk-do, Jeju-do, and Incheon Metropolitan City) (Table 3). Collected hard ticks included 546 H. longicornis (59 adults, 129 nymphs, and 358 larvae) and $32 \mathrm{H}$. flava (1 adult, 19 nymphs, and 12 larvae).

In total, 9,028 hard ticks were collected from 8 habitats of wild boars (Table 4). Only 1 habitat was selected to collect ticks in each province. The most common species was $\mathrm{H}$. longicornis (4,347: 177 adults, 470 nymphs, and 3,700 larvae), followed by 4,172 H. flava (133 adults, 806 nymphs, and 3,233 larvae), 508 I. nipponensis (16 adults, 20 nymphs, and 472 larvae), and 1 I. turdus (1 nymph).

Soft ticks were not found from grazing or traditionally reared domestic pigs, wild boars, and their habitats.

\section{DISCUSSION}

H. longicornis was the most common species (50.5\%) of all

Table 3. Ticks collected from grazing or traditionally reared domestic pig farms and near the areas using the dragging and flagging methods, 2013

\begin{tabular}{|c|c|c|c|c|c|c|c|}
\hline \multirow{2}{*}{ Province } & \multirow{2}{*}{$\begin{array}{c}\text { No. of } \\
\text { collection sites }\end{array}$} & \multirow{2}{*}{ Tick species } & \multirow{2}{*}{ No. of larvae } & \multirow{2}{*}{ No. of nymphs } & \multicolumn{2}{|c|}{ No. adults } & \multirow{2}{*}{$\begin{array}{l}\text { Total no. of ticks } \\
\text { collected }\end{array}$} \\
\hline & & & & & Male & Female & \\
\hline \multirow[t]{3}{*}{ Gangwon-do } & 2 & H. longicornis & 0 & 0 & 7 & 6 & 13 \\
\hline & & H. flava & 0 & 2 & 0 & 0 & 2 \\
\hline & & Subtotal & 0 & 2 & 7 & 6 & 15 \\
\hline \multirow[t]{3}{*}{ Gyeonggi-do } & 1 & H. longicornis & 46 & 17 & 2 & 3 & 68 \\
\hline & & H. flava & 0 & 1 & 0 & 0 & 1 \\
\hline & & Subtotal & 46 & 18 & 2 & 3 & 69 \\
\hline \multirow[t]{3}{*}{ Chungcheongbuk-do } & 2 & H. longicornis & 23 & 14 & 0 & 6 & 43 \\
\hline & & H. flava & 0 & 0 & 0 & 0 & 0 \\
\hline & & Subtotal & 23 & 14 & 0 & 6 & 43 \\
\hline \multirow[t]{3}{*}{ Chungcheongnam-do } & 4 & H. longicornis & 11 & 17 & 0 & 3 & 31 \\
\hline & & H. flava & 0 & 5 & 0 & 1 & 6 \\
\hline & & Subtotal & 11 & 22 & 0 & 4 & 37 \\
\hline \multirow[t]{3}{*}{ Jeollabuk-do } & 8 & H. longicornis & 231 & 29 & 0 & 19 & 279 \\
\hline & & H. flava & 0 & 6 & 0 & 0 & 6 \\
\hline & & Subtotal & 231 & 35 & 0 & 19 & 285 \\
\hline \multirow[t]{3}{*}{ Jeollanam-do } & 2 & H. longicornis & 0 & 8 & 0 & 0 & 8 \\
\hline & & H. flava & 0 & 0 & 0 & 0 & 0 \\
\hline & & Subtotal & 0 & 8 & 0 & 0 & 8 \\
\hline \multirow[t]{3}{*}{ Gyeongsangbuk-do } & 2 & H. longicornis & 23 & 0 & 0 & 2 & 25 \\
\hline & & H. flava & 0 & 0 & 0 & 0 & 0 \\
\hline & & Subtotal & 23 & 0 & 0 & 2 & 25 \\
\hline \multirow[t]{3}{*}{ Jeju-do } & 1 & H. longicornis & 22 & 16 & 2 & 3 & 43 \\
\hline & & H. flava & 0 & 4 & 0 & 0 & 4 \\
\hline & & Subtotal & 22 & 20 & 2 & 3 & 47 \\
\hline \multirow[t]{3}{*}{ Incheon Metropolitan City } & 2 & H. longicornis & 2 & 28 & 0 & 6 & 36 \\
\hline & & H. flava & 12 & 1 & 0 & 0 & 13 \\
\hline & & Subtotal & 14 & 29 & 0 & 6 & 49 \\
\hline \multirow[t]{3}{*}{ Total (8 provinces, 1 city) } & 24 & H. longicornis & 358 & 129 & 11 & 48 & 546 \\
\hline & & H. flava & 12 & 19 & 0 & 1 & 32 \\
\hline & & Total & 370 & 148 & 11 & 49 & 578 \\
\hline
\end{tabular}


the ticks collected from wild boars and swine habitats. According to a previous study, H. longicornis was the predominant species on the Korean peninsula [12]. Another study also showed that $H$. longicornis was readily found in the grasses and herbaceous vegetation of large herbivore habitats [13]. Medium-to-large-sized mammals inhabiting grasses and herbaceous vegetation habitats are the known main hosts of $H$. longicornis [14]. This study used similar methods of dragging and flagging to collect $H$. longicornis mostly in habitats of domestic pigs and wild boars. The dominant tick species collected di- rectly form wild boars and the habitats was $\mathrm{H}$. flava (45.4\% from wild boars and $57.9 \%$ from their habitats), except the larval stage. H. flava is known to parasitize small-to-mediumsized mammals and resident/migratory birds and is primarily observed in conifer and mixed forest habitats [13]. Usually, the habitats of wild boars are unmanaged, with tall grasses, conifers, and forested vegetation, which was identical to our habitats used in this study. I. nipponensis and A. testudinarium were collected only directly from wild boars in this study. I. nipponensis is a 2-host tick that feeds on small-to-medium-

Table 4. Ticks collected from the habitats of wild boars, 2013

\begin{tabular}{|c|c|c|c|c|c|c|c|}
\hline \multirow{2}{*}{ Province } & \multirow{2}{*}{$\begin{array}{c}\text { No. of } \\
\text { collection sites }\end{array}$} & \multirow{2}{*}{ Tick species } & \multirow{2}{*}{ No. of larvae } & \multirow{2}{*}{ No. of nymphs } & \multicolumn{2}{|c|}{ No. adults } & \multirow{2}{*}{$\begin{array}{c}\text { Total no. of ticks } \\
\text { collected }\end{array}$} \\
\hline & & & & & Male & Female & \\
\hline \multirow[t]{4}{*}{ Gangwon-do } & 1 & H. longicornis & 321 & 31 & 0 & 2 & 354 \\
\hline & & H. flava & 161 & 26 & 3 & 1 & 191 \\
\hline & & I. nipponensis & 31 & 0 & 0 & 0 & 31 \\
\hline & & Subtotal & 513 & 57 & 3 & 3 & 576 \\
\hline \multirow{3}{*}{ Gyeonggi-do } & & H. flava & 203 & 46 & 11 & 4 & 264 \\
\hline & & I. nipponensis & 250 & 6 & 0 & 0 & 256 \\
\hline & & Subtotal & 693 & 58 & 11 & 6 & 768 \\
\hline \multirow[t]{3}{*}{ Chungcheongbuk-do } & 1 & H. longicornis & 1,069 & 11 & 2 & 10 & 1,092 \\
\hline & & H. flava & 558 & 177 & 17 & 8 & 760 \\
\hline & & I. nipponensis & 35 & 8 & 2 & 1 & 46 \\
\hline \multirow[t]{4}{*}{ Chungcheongnam-do } & 1 & H. longicornis & 716 & 41 & 1 & 28 & 786 \\
\hline & & H. flava & 317 & 155 & 5 & 5 & 482 \\
\hline & & I. nipponensis & 0 & 0 & 0 & 0 & 0 \\
\hline & & Subtotal & 1,033 & 196 & 6 & 33 & 1,268 \\
\hline \multirow[t]{4}{*}{ Jeollabuk-do } & 1 & H. longicornis & 166 & 13 & 1 & 11 & 191 \\
\hline & & H. flava & 1,299 & 211 & 16 & 29 & 1,522 \\
\hline & & I. nipponensis & 136 & 3 & 2 & 3 & 144 \\
\hline & & Subtotal & 1,601 & 227 & 19 & 43 & 1,857 \\
\hline \multirow[t]{4}{*}{ Jeollanam-do } & 1 & H. flava & 405 & 52 & 6 & 9 & 472 \\
\hline & & H. longicornis & 123 & 19 & 1 & 8 & 151 \\
\hline & & I. nipponensis & 2 & 2 & 1 & 0 & 5 \\
\hline & & Subtotal & 530 & 73 & 8 & 17 & 628 \\
\hline \multirow[t]{2}{*}{ Gyeongsangbuk-do } & 1 & H. longicornis & 548 & 324 & 13 & 43 & 928 \\
\hline & & Subtotal & 712 & 348 & 15 & 43 & 1,118 \\
\hline \multirow[t]{5}{*}{ Gyeongsangnam-do } & 1 & H. longicornis & 517 & 2 & 0 & 0 & 519 \\
\hline & & H. flava & 135 & 132 & 25 & 9 & 301 \\
\hline & & I. nipponensis & 9 & 0 & 7 & 0 & 16 \\
\hline & & I. turdus & 0 & 1 & 0 & 0 & 1 \\
\hline & & Subtotal & 661 & 135 & 32 & 9 & 837 \\
\hline \multirow[t]{5}{*}{ Total } & 8 & H. longicornis & 3,700 & 470 & 27 & 150 & 4,347 \\
\hline & & H. flava & 3,233 & 806 & 82 & 51 & 4,172 \\
\hline & & I. nipponensis & 472 & 20 & 12 & 4 & 508 \\
\hline & & I. turdus & 0 & 1 & 0 & 0 & 1 \\
\hline & & Total & 7,405 & 1,297 & 121 & 205 & 9,028 \\
\hline
\end{tabular}


sized mammals during the larval and nymphal stages, and medium-to-large-sized mammals during the nymph and adult stages. I. nipponensis was not amenable to collection by dragging and flagging methods either in other research or in our study [14]. A. testudinarium has a host-seeking strategy, while other species collected in this study have a passive ambushing strategy. As such, it was hard to find A. testudinarium by the dragging and sweeping method.

There are 4 ways to collect ticks, i.e., flagging and dragging, carbon dioxide baits, direct collection from hosts, and walking [15]. In this study, only dragging and flagging on the ground and direct collection from hosts were used. The dragging and flagging methods are most commonly used to collect unfed ticks. The vibration produced by moving cloth is recognized by ticks as similar to that from a potential host, so that ticks attach to the cloth. The dragging and flagging method can provide an approximate density of questing tick species populations in selected areas. However, this method tends to collect only limited tick species, such as $H$. longicornis and $H$. flava, as was the case in this study. As such, ticks were also collected directly from wild boars for a more diverse and accurate estimate of tick populations. The distribution of ticks collected from porcine species can be used to determine the prevalence of ticks and investigate tick-related porcine diseases.

There are few studies in the ROK of tick species that parasitize wild boars [16]. Moreover, there is no study of ticks and porcine species in general. However, many countries have investigated various tick-borne diseases from wild boars. For example, tick-borne encephalitis in the Czech Republic and Anaplasma phagocytophilum, Borrelia burgdorferi, and Rickettsia spp. in Germany were reported $[17,18]$. As wild boars are becoming vectors for many diseases [4], there are some concerns that new vectors and diseases from other countries could be imported with wild animals into the ROK, including wild boars. In addition, due to the expansion of the ranges of many wild animals, diseases that can infect different species may be more likely to spread.

Ornithodoros spp., the main vector of ASF, was not found in this study. However, the first detection of Ornithodoros spp. was reported in the ROK in 2015. In total, 12 O. sawaii were collected from the habitats of Synthliboramphus antiquus and Hydrobates monorhis on Chilbal Island, which is an uninhabited island in Jeollanam-do, ROK. A total of 2 females, 4 males, and 6 nymphs of Ornithodoros spp. were collected [19]. However, there was no report that O. sawaii was infected by ASFV [20], and it is essential to investigate ASFV in vector ticks and hosts in near areas because it can be transmitted through ticks attached on host animals.

Ticks and tick-borne diseases can spread for many reasons. Tick populations can move with climate change, host movements, and landscape modifications [3]. In addition, tickborne pathogens can be transmitted by vector ticks and reservoir animals. Almost any kind of animals can host ticks and vectors of tick-borne diseases. This study investigated only the ticks that parasitize porcine species, as many studies have indicated that the number of wild boars is increasing [21,22], which might be closely related to the transmission of ticks and tick-borne diseases. Other wild animals besides wild boars are important in the dispersal of ticks and tick-borne diseases, and therefore, it is necessary to investigate ticks that parasitize all wild animals.

\section{ACKNOWLEDGMENT}

This research was supported by a fund (no. Z-15417822013-13-01) from Research of Animal and Plant Quarantine Agency, South Korea and was also partially supported by the Research Institute for Veterinary Science, Seoul National University. I would like to thanks to the Korean Wildlife Management Association for the help of collecting ticks from wild boars.

\section{CONFLICT OF INTEREST}

We have no conflict of interest related to this work.

\section{REFERENCES}

1. Horak IG, Camicas JL, Keirans JE. The Argasidae, Ixodidae and Nuttalliellidae (Acari: Ixodida): a world list of valid tick names. Exp Appl Acarol 2002; 28: 27-54.

2. Klompen JSH, Black WC, Keirans JE, Oliver JH, Jr. Evolution of ticks. Annu Rev Entomol 1996; 41: 141-161.

3. Leger E, Vourc'h G, Vial L, Chevillon C, McCoy KD. Changing distributions of ticks: causes and consequences. Exp Appl Acarol 2013; 59: 219-244.

4. Meng XJ, Lindsay DS, Sriranganathan N. Wild boars as sources for infectious diseases in livestock and humans. Philos Trans R Soc Lond B Biol Sci 2009; 364: 2697-2707.

5. Møller AP, Merino S, Soler JJ, Antonov A, Badás EP, Calero-Torralbo MA, de Lope F, Eeva T, Figuerola J, Flensted-Jensen E, Garamszegi LZ, González-Braojos S, Gwinner H, Hanssen SA, Hey- 
len D, Ilmonen P, Klarborg K, Korpimäki E, Martínez J, Martínez-de la Puente J, Marzal A, Matthysen E, Matyjasiak P, Molina-Morales M, Moreno J, Mousseau TA, Nielsen JT, Pap PL, Rivero-de Aguilar J, Shurulinkov P, Slagsvold T, Szép T, Szöllősi E, Török J, Vaclav R, Valera F, Ziane N. Assessing the effects of climate on host-parasite interactions: a comparative study of European birds and their parasites. PLoS One 2013; 8: e82886.

6. Bieber C, Ruf T. Population dynamics in wild boar Sus scrofa: ecology, elasticity of growth rate and implications for the management of pulsed resource consumers. J Appl Ecol 2005; 42: 1203-1213.

7. IUCN I. Red List of Threatened Species: Version 2011.2. 2012.

8. Burrage TG. African swine fever virus infection in Ornithodoros ticks. Virus Res 2013; 173: 131-139.

9. Ravaomanana J, Michaud V, Jori F, Andriatsimahavandy A, Roger F, Albina E, Vial L. First detection of African Swine Fever Virus in Ornithodoros porcinus in Madagascar and new insights into tick distribution and taxonomy. Parasit Vectors 2010; 3: 115.

10. Daniels TJ, Boccia TM, Varde S, Marcus J, Le J, Bucher DJ, Falco $\mathrm{RC}$, Schwartz I. Geographic risk for lyme disease and human granulocytic ehrlichiosis in southern New York state. Appl Environ Microbiol 1998; 64: 4663-4669.

11. Yamaguti N, Tipton VJ, Keegan HL, Toshioka S. Ticks of Japan, Korea, and the Ryukyu islands. Brigham Young University Science Bulletin-Biological Series 1971; 15: 1-226.

12. Hoogstraal H. Argasid and nuttalliellid ticks as parasites and vectors. Adv Parasitol 1985; 24: 135-238.

13. Chong ST, Kim HC, Lee IY, Kollars TM Jr, Sancho AR, Sames WJ, Chae JS, Klein TA. Seasonal distribution of ticks in four habitats near the demilitarized zone, Gyeonggi-do (Province), Republic of Korea. Korean J Parasitol 2013; 51: 319-325.

14. Kim HC, Chong ST, Sames WJ, Nunn PV, Wolf SP, Robbins RG,
Klein TA. Tick surveillance of small mammals captured in Gyeonggi and Gangwon Provinces, Republic of Korea, 20042008. Syst Appl Acarol 2010; 15: 100-108.

15. Gray JS. A carbon dioxide trap for prolonged sampling of Ixodes ricinus L. populations. Exp Appl Acarol 1985; 1: 35-44.

16. Kim BJ, Kim H, Won S, Kim HC, Chong ST, Klein TA, Kim KG, Seo HY, Chae JS. Ticks collected from wild and domestic animals and natural habitats in the Republic of Korea. Korean J Parasitol 2014; 52: 281-285.

17. Kriz B, Daniel M, Benes C, Maly M. The role of game (wild boar and roe deer) in the spread of tick-borne encephalitis in the Czech Republic. Vector Borne Zoonotic Dis 2014; 14: 801-807.

18. Silaghi C, Pfister K, Overzier E. Molecular investigation for bacterial and protozoan tick-borne pathogens in wild boars (Sus scrofa) from southern Germany. Vector Borne Zoonotic Dis 2014; 14 : 371-373.

19. Kim HC, Park CU, Park JH, Kwon YS, Yun SM, Lee WJ, Chong ST, Lee IY, Klein TA, Robbins RG. Ornithodoros sawaii Kitaoka and Suzuki (Acari: Ixodida: Argasidae) collected from nest soil and litter of Synthliboramphus antiquus and Hydrobates monorhis, on Chilbal Island, southwestern Jeollanam Province, Republic of Korea. Syst Appl Acarol 2015; 20: 721-730.

20. Kleiboeker SB, Scoles GA. Pathogenesis of African swine fever virus in Ornithodoros ticks. Anim Health Res Rev 2001; 2: 121-128.

21. Massei G, Kindberg J, Licoppe A, Gačić D, Šprem N, Kamler J, Baubet E, Hohmann U, Monaco A, Ozolinšs J. Wild boar populations up, numbers of hunters down? A review of trends and implications for Europe. Pest Managem Sci 2015; 71: 492-500.

22. Kim SO, Kwon IK, Kim TS, Ko HS, Jang GS. An analysis on aspects of farm lands damaged by the wild boar (Sus scrofa) in Gyeongnam Province, Korea. J Korean Soc Environ Restor Technol 2014; 17: 17-27. 
